\title{
Comparison of the effects of four commercially available weight-loss programmes on lipid-based cardiovascular risk factors
}

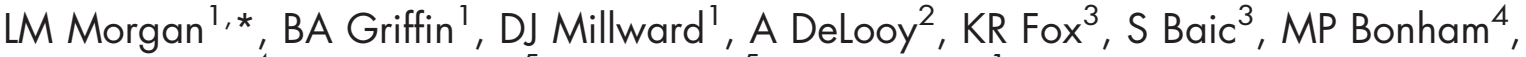 \\ JMW Wallace ${ }^{4}$, I MacDonald ${ }^{5}$, MA Taylor ${ }^{5}$ and $\mathrm{H}_{\text {Truby }}{ }^{1}$ \\ ${ }^{1}$ School of Biomedical and Molecular Sciences, University of Surrey, Guildford, Surrey, GU2 7XH, UK: ${ }^{2}$ Queen \\ Margaret University College, Edinburgh EH12 8TS, UK: ${ }^{3}$ Department of Exercise, Nutrition and Health Sciences, \\ University of Bristol, Bristol BS8 1TP, UK: ${ }^{4}$ Northern Ireland Centre for Food and Health, University of Ulster, \\ Coleraine BT52 1SA, UK: ${ }^{5}$ School of Biomedical Sciences, University of Nottingham, Nottingham NG7 2UH, UK
}

Submitted 26 July 2007: Accepted 7 May 2008: First published online 23 July 2008

\begin{abstract}
Objective: To investigate the relative efficacy of four popular weight-loss programmes on plasma lipids and lipoproteins as measures of CVD risk.

Design: A multi-centred, randomised, controlled trial of four diets - Dr Atkins' New Diet Revolution, The Slim-Fast Plan, Weight Watchers Pure Points programme and Rosemary Conley's 'Eat yourself Slim' Diet and Fitness Plan - against a control diet, in parallel for 6 months.

Setting and subjects: The trial was conducted at five universities across the UK (Surrey, Nottingham, Ulster (Coleraine), Bristol and Edinburgh (Queen Margaret University College)) and involved the participation of 300 overweight and obese males and females aged 21-60 years in a community setting.

Results: Significant weight loss was achieved by all dieting groups $(5-9 \mathrm{~kg}$ at 6 months) but no significant difference was observed between diets at 6 months. The Weight Watchers and Rosemary Conley (low-fat) diets were followed by significant reductions in plasma LDL cholesterol (both $-12 \cdot 2 \%$ after 6 months, $P<0 \cdot 01$ ), whereas the Atkins (low-carbohydrate) and Weight Watchers diets were followed by marked reductions in plasma TAG $(-38 \cdot 2 \%$ and $-22 \cdot 6 \%$ at 6 months respectively, $P<0 \cdot 01)$. These latter two diets were associated with an increase in LDL particle size, a change that has been linked to reduced CVD risk. Conclusions: Overall, these results demonstrate the favourable effects of weight loss on lipid-mediated CVD risk factors that can be achieved through commercially available weight-loss programmes. No detrimental effects on lipid-based CVD risk factors were observed in participants consuming a low-carbohydrate diet.
\end{abstract}

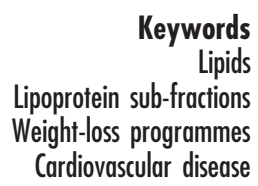

The prevalence of obesity in the UK is increasing, with $41 \%$ of adult men and $33 \%$ of women being overweight and an additional $25 \%$ and $20 \%$ respectively being obese $^{(1)}$. As the health, economic and social costs of obesity have become increasingly apparent, the number and variety of weight-loss programmes has multiplied. Numerous dieting programmes are currently available that focus on different strategies for reducing energy intake, by restricting specific macronutrients (fat or carbohydrate), controlling portion size or replacing meals with substitutes.

Obesity is one of the major modifiable risk factors for CVD. Weight loss per se results in favourable changes in blood lipid profiles, decreasing circulating LDL cholesterol (LDL-C) and TAG levels and increasing HDL cholesterol (HDL-C) if weight loss is maintained ${ }^{(2)}$.
However, restriction of specific macronutrients can produce differential effects on lipid profiles. High-carbohydrate, low-fat diets, while decreasing LDL-C, have a tendency to increase plasma TAG concentrations and decrease HDL-C ${ }^{(3)}$, whereas low-carbohydrate diets, though effective in lowering plasma TAG concentrations, can be inherently high in saturated fat and cholesterol and show variable effects on LDL-C ${ }^{(4-8)}$.

Obesity is frequently associated with raised plasma TAG and a predominance of small, dense LDL particles. This type of LDL, or LDL phenotype, is also found in CHD patients and has been associated with up to a threefold increase in risk of $\mathrm{CHD}^{(9,10)}$. There is evidence to suggest that the cholesterol-lowering effect of both low-fat (high-carbohydrate) and high-fat (low-carbohydrate) diets is much greater in people with a small, dense LDL phenotype ${ }^{(11)}$. 
While few studies have been carried out on the effect of weight loss on different LDL phenotypes, low-carbohydrate, low-energy diets have also been shown to increase LDL particle size; but these studies have been of short duration and with small subject numbers ${ }^{(12-14)}$. Furthermore, with the notable exception of one recent study ${ }^{(15)}$, there have been few direct comparisons of the efficacy of commercially available weight-loss programmes in modifying blood lipids and lipoproteins. The present multi-centred study, the largest in the UK to date, was designed to examine the efficacy of four popular weightloss programmes, in a randomised controlled design, on a range of outcome variables related to weight loss, body composition and biochemical variables that have been reported elsewhere ${ }^{(16,17)}$. The current paper reports the effects of these diets on plasma lipid and lipoproteins as markers of CVD risk.

\section{Methods}

\section{Weight-loss programmes}

The trial involved five study groups: four weight-loss regimes that were chosen as being representative of the major different approaches to weight management in the UK and a control group. The diets were: (i) The Slim-Fast Plan (a low-fat meal replacement approach); (ii) Weight Watchers Pure Points programme (an energy-controlled low-fat healthy eating diet); (iii) Dr Atkins' New Diet Revolution (a low-carbohydrate diet); and (iv) Rosemary Conley's 'Eat yourself Slim' Diet and Fitness Plan (an energycontrolled low-fat healthy eating diet + weekly group exercise class). The control was a delayed treatment group which involved no dietary intervention until after 6 months.

\section{Study setting, subjects and design}

Three hundred overweight and obese men and women were recruited via a BBC advertising campaign at five university centres across the UK, i.e. Surrey (Guildford), Nottingham, Ulster (Coleraine), Bristol and Edinburgh (Queen Margaret University College). Each centre aimed to recruit a cohort of sixty participants, to allow twelve in each diet group plus a further twelve in a control group. Subjects were chosen from people aged 18 to 65 years who lived within 30 miles of a test centre and had a selfreported BMI between 27 and $40 \mathrm{~kg} / \mathrm{m}^{2}$. Those who fulfilled these preliminary inclusion criteria were deemed eligible for the study after confirmation from their general practitioner, based on the following exclusion criteria: prior history of CHD, known type 1 or 2 diabetes, liver or respiratory failure, gout, lipid-lowering or anti-hypertensive medication, history of obesity with known cause (i.e. Cushing's syndrome, hypothyroidism), previous gastric or weight-loss surgery, taking any weight-losing drugs (including Orlistat or Sibutramine), clinical depression, eating disorders, drug or alcohol abuse, any malabsorptive state (including lactose intolerance), treatment for a malignancy, pregnancy or breast-feeding. Participants gave their informed written consent to take part in the study. Ethical approval was obtained from the South East Multi-centre Research Ethics Committee.

Participants were stratified by gender (only 30\% of participants were male) and randomly allocated to any of the five groups (four diets and control). Each participant undertook the diet to which they had been assigned for 6 months. For the group-based programmes (Weight Watchers and Rosemary Conley), participants arranged to attend the most geographically convenient class and the costs of joining and attending one class per week for 6 months were reimbursed on presentation of receipts. Both parent companies of Weight Watchers (www.weightwatchers.co. uk) and Rosemary Conley (www.rosemary-conley.co.uk) signed a contract committing to the provision of standard care. For Slim-Fast, the cost of up to two meal replacements per day was reimbursed on presentation of receipts, and a copy of the Slim-Fast Support Pack was provided. The Atkins group was given a copy of Dr Atkins' New Diet Revolution $^{(18)}$. Control group subjects were asked to maintain their current diet and exercise pattern and were offered any of the diets for 6 months at the end of study, free of charge. All participants were able to claim reimbursement of travel costs. Diet group participants were instructed to follow the specific guidelines for each dietary programme, and every effort was made to avoid investigator management of, or interference in, participants' food intakes.

Participants attended the test centres on a 4-weekly basis, where they were weighed in light clothing and their blood pressure and waist circumference was measured. A fasting venous blood sample was taken from all participants at baseline, and after 8 and 24 weeks for the measurement of insulin, glucose and plasma lipids. Additional blood samples were taken monthly from the Atkins group to monitor renal function (urea, electrolytes and cystatin C).

\section{Dietary analyses}

Participants were asked to complete a $7 \mathrm{~d}$ diet diary at baseline, 8 and 24 weeks, using a previously validated diary based on household measures. Diaries were checked for completeness and energy and macronutrient composition were calculated using nutrient analysis software (Windiets Research Version; The Robert Gordon University, Aberdeen, UK).

\section{Biochemical analyses}

Plasma glucose, TAG, HDL-C and LDL-C were measured by standard automated spectrophotometric methods (reagent kits from Randox, County Antrim, UK). The inter-assay $\mathrm{CV}$ were $<5 \%$ for these assays. Insulin was measured by an immunochemiluminometric assay (Molecular Light Technologies, Cardiff, UK). The inter-assay CV was $<10 \%$. Insulin sensitivity was calculated by the homeostasis model assessment (HOMA) ${ }^{(19)}$. LDL particle size was 
determined by iodixanol density gradient centrifugation as previously described ${ }^{(20,21)}$. Cystatin C was measured by an automated immunoturbidimetric method ${ }^{(22)}$. Blood samples from all visits (baseline, 2 and 6 months) were analysed for each individual within a single batch for all biochemical analyses.

\section{Statistical analyses}

Analyses are reported for all completing participants, defined as those with data available at each of three time points: baseline, week 8 and week 24 . The final drop-out rate was $28 \%$. ANOVA showed no effect of test centre on either anthropometric or demographic measures, total weight loss in completing participants, or total drop-out rate. Data for all participants were therefore analysed together. Changes in metabolic variables over time were examined by repeated measures ANOVA (with 'time' as the within-subject factor and 'diet group' as the betweensubject factor). Comparisons between diets for metabolic variables at 6 months were examined by analysis of covariance, with diet group and gender as between-subject factors and baseline measurements as covariates. Post hoc comparisons for differences between groups were located using the Tukey Honest Significant Difference test. Associations between weight loss, plasma lipids and insulin were tested using the Pearson's correlation. Data are reported as means and their standard errors unless otherwise stated and $P$ values of $<0.05$ were considered statistically significant. Data were analysed using the Statistica statistical software package (Statsoft, Tulsa, OK, USA).

\section{Results}

\section{Baseline characteristics}

Demographic and anthropometric measures of the groups are shown in Table 1 . There were no significant differences in baseline characteristics between the groups.

\section{Dietary analyses}

A summary of macronutrient and energy intakes at baseline, 2 and 6 months, for those subjects returning complete $7 \mathrm{~d}$ diaries, is shown in Table 2 . The dietary data have also been partly reported elsewhere ${ }^{(15)}$. The diet at baseline comprised on average $37 \%$ fat, $42 \%$ carbohydrate, $16 \%$ protein and $5 \%$ alcohol (percentage of energy), and showed no differences between groups. Predicted changes in macronutrient composition occurred over the course of the study. Thus, there was a marked reduction (66-80\%) in carbohydrate intake on the Atkins diet and reductions of between 30 and $50 \%$ in fat intake on the other three diets. On average, mean daily energy intake fell by $30 \%$ on the four diets compared with baseline values, but decreased much less (10\%) in the control group after 2 months of dieting.

\section{Changes in body weight}

Absolute weights at baseline, 2 and 6 months are shown in Table 3. There was significant weight loss between baseline and both 2 and 6 months in all four dieting groups $(P<0 \cdot 001)$. However, no significant differences in weight loss between diets were observed at 6 months. There was no significant change in weight in the control group. A full examination of weight outcomes has been reported previously ${ }^{(17)}$. Markers of renal function were maintained within normal limits for all Atkins participants.

\section{Relationships between reported dietary intake and weight loss}

Within those participants for whom food intake was successfully measured, there was no significant difference between diet groups in the fall in energy intakes (the difference between energy intake at baseline and at 2 and 6 months) or weight loss at 2 or 6 months. An analysis of the relationship between individual weight loss and the fall in energy intakes showed, for the cohort as a whole,

Table 1 Baseline demographic and anthropometric data of participants by diet group: UK multi-centred, randomised controlled trial of the effects of four commercially available weight-loss programmes on lipid-based CVD risk factors

\begin{tabular}{|c|c|c|c|c|c|c|}
\hline & $\begin{array}{c}\text { Atkins } \\
(\mathrm{n} \mathrm{57)} \\
(15 \mathrm{M}, 42 \mathrm{~F})\end{array}$ & $\begin{array}{c}\text { Weight Watchers } \\
(n 58) \\
(16 \mathrm{M}, 42 \mathrm{~F})\end{array}$ & $\begin{array}{c}\text { Slim-Fast } \\
(n \text { 59) } \\
(17 \mathrm{M}, 42 \mathrm{~F})\end{array}$ & $\begin{array}{c}\text { Rosemary Conley } \\
(n 58) \\
(16 \mathrm{M}, 42 \mathrm{~F})\end{array}$ & $\begin{array}{c}\text { Control } \\
(n 61) \\
(15 \mathrm{M}, 46 \mathrm{~F})\end{array}$ & $\begin{array}{l}\text { Whole cohort } \\
(n 293) \\
(79 \mathrm{M}, 214 \mathrm{~F})\end{array}$ \\
\hline \multicolumn{7}{|c|}{ Age (years) } \\
\hline Mean & $40 \cdot 9$ & $39 \cdot 9$ & $38 \cdot 9$ & $40 \cdot 6$ & $40 \cdot 8$ & $40 \cdot 3$ \\
\hline SD & $9 \cdot 7$ & $10 \cdot 9$ & $10 \cdot 7$ & $10 \cdot 3$ & $9 \cdot 6$ & $10 \cdot 2$ \\
\hline \multicolumn{7}{|c|}{ BMI $\left(\mathrm{kg} / \mathrm{m}^{2}\right)$} \\
\hline Mean & $31 \cdot 9$ & $31 \cdot 2$ & $32 \cdot 2$ & $31 \cdot 6$ & $31 \cdot 5$ & $31 \cdot 7$ \\
\hline SD & $2 \cdot 2$ & $2 \cdot 7$ & $3 \cdot 0$ & $2 \cdot 6$ & $2 \cdot 9$ & $2 \cdot 7$ \\
\hline \multicolumn{7}{|c|}{ Waist circumference $(\mathrm{cm})$} \\
\hline Mean & $102 \cdot 0$ & $100 \cdot 0$ & $101 \cdot 0$ & $100 \cdot 0$ & $100 \cdot 0$ & $101 \cdot 0$ \\
\hline SD & $10 \cdot 6$ & $10 \cdot 3$ & 11.5 & $9 \cdot 8$ & $10 \cdot 1$ & $10 \cdot 4$ \\
\hline \multicolumn{7}{|c|}{ Systolic blood pressure $(\mathrm{mmHg})$} \\
\hline Mean & $135 \cdot 0$ & $127 \cdot 0$ & $129 \cdot 0$ & $130 \cdot 0$ & $130 \cdot 0$ & $131 \cdot 0$ \\
\hline SD & $15 \cdot 1$ & $15 \cdot 1$ & $17 \cdot 0$ & $14 \cdot 8$ & $16 \cdot 1$ & $15 \cdot 6$ \\
\hline \multicolumn{7}{|c|}{ Diastolic blood pressure $(\mathrm{mmHg})$} \\
\hline Mean & $83 \cdot 0$ & $80 \cdot 0$ & $81 \cdot 0$ & $82 \cdot 0$ & $81 \cdot 0$ & $82 \cdot 0$ \\
\hline SD & $10 \cdot 7$ & $10 \cdot 7$ & $11 \cdot 5$ & $10 \cdot 3$ & $9 \cdot 6$ & $10 \cdot 4$ \\
\hline
\end{tabular}

M, males; F, females. 
that at 2 months weight loss was significantly related to the fall in energy intake $(r=0 \cdot 40, P<0 \cdot 001, n 162)$ but at 6 months the weight loss was not significantly related to the fall in energy intake $(r=0 \cdot 23, P=0 \cdot 115, n 47)$, although food intake was successfully measured only in forty-seven subjects at 6 months. Within individual dietary groups, weight loss at 2 months was related to the fall in energy intakes only for Rosemary Conley $(r=0 \cdot 50$, $P<0.005)$ and Slim-Fast $(r=0.51, P<0.002)$ groups, while at 6 months there was a significant relationship only for the Slim-Fast group $(r=0 \cdot 63, P=0 \cdot 049)$.

\section{Changes in plasma lipids and lipoproteins within and between dietary groups}

Mean values of plasma lipids and lipoproteins are shown in Table 3. Plasma LDL-C concentrations decreased significantly in the Weight Watchers, Slim-Fast and Rosemary Conley groups after 6 months compared with basal values, but were unchanged for the Atkins group. Plasma TAG concentrations decreased significantly in the Atkins, Weight Watchers and Rosemary Conley groups, but were unchanged in the Slim-Fast group. HDL-C was unchanged at 6 months compared with basal values in the Atkins groups, but decreased significantly in all other groups, including the control group.

Changes in plasma lipid and lipoprotein concentrations between 0 and 6 months are shown in Fig. 1. There was a significant effect of diet on plasma LDL-C $(P=0 \cdot 0005)$, TAG $(P<0 \cdot 021)$ and HDL-C $(P=0 \cdot 018)$ after adjustment for baseline values, but no effect of gender. There was no significant effect of diet on the ratio of total cholesterol to HDL-C.

\section{Changes in LDL particle size at 6 months between groups; association with plasma LDL cholesterol and TAG}

LDL peak density decreased within all dietary groups, indicating an increase in LDL particle size (Fig. 2). There was a significant effect of diet on LDL density $(P=0 \cdot 003)$ across groups after adjusting for baseline values but no effect of gender. The decrease in LDL peak density (increase in LDL particle size) was significantly greater than the control only in the Atkins group. While the effects of the four diets on LDL-C were unrelated to LDL particle size, the reductions in plasma TAG after 6 months were respectively three- and ninefold greater in subjects with a predominance of small, dense LDL at baseline on the Atkins $(P=0.003)$ and Weight Watchers $(P<0 \cdot 001)$ diets (Fig. 3).

\section{Changes in plasma insulin and glucose witbin and between dietary groups}

Mean plasma insulin was decreased after 6 months in all dieting groups, compared with a small rise in insulin in the control group. There were no differences between the dieting groups but evidence of a diet-gender interaction $(P=0 \cdot 045)$. Changes in glucose levels showed no effect 
Table 3 Weight and lipid-based CVD disease risk factors in participants at baseline, 2 and 6 months for control and diet groups: UK multicentred, randomised controlled trial of the effects of four commercially available weight-loss programmes on lipid-based CVD risk factors

\begin{tabular}{|c|c|c|c|c|c|c|c|c|c|c|}
\hline & \multicolumn{2}{|c|}{ Atkins } & \multicolumn{2}{|c|}{ Weight Watchers } & \multicolumn{2}{|c|}{ Slim-Fast } & \multicolumn{2}{|c|}{ Rosemary Conley } & \multicolumn{2}{|c|}{ Control } \\
\hline & Mean & SD & Mean & SD & Mean & SD & Mean & SD & Mean & SD \\
\hline \multicolumn{11}{|l|}{ Weight $(\mathrm{kg})$} \\
\hline Baseline & $92 \cdot 1$ & $13 \cdot 6$ & $89 \cdot 4$ & $13 \cdot 6$ & $92 \cdot 1$ & $14 \cdot 3$ & $88 \cdot 2$ & $13 \cdot 1$ & $87 \cdot 6$ & $14 \cdot 6$ \\
\hline 2 months & $85 \cdot 1^{\star \star}$ & $10 \cdot 9$ & $84 \cdot 2^{\star \star}$ & $13 \cdot 2$ & $87 \cdot 2^{\star \star}$ & $12 \cdot 4$ & $82 \cdot 8^{\star \star}$ & $12 \cdot 4$ & $86 \cdot 9$ & $14 \cdot 8$ \\
\hline 6 months & $83 \cdot 2^{\star \star}$ & $10 \cdot 6$ & $81 \cdot 4^{\star *}$ & $13 \cdot \overline{6}$ & $85 \cdot 4^{\star \star}$ & $12 \cdot 2$ & $79 \cdot 4^{\star *}$ & $12 \cdot 6$ & $88 \cdot 5$ & $15 \cdot 0$ \\
\hline \multicolumn{11}{|l|}{ TAG $(\mathrm{mmol} / \mathrm{l})$} \\
\hline Baseline & 1.65 & $0 \cdot 70$ & $1 \cdot 55$ & 0.77 & 1.49 & 1.00 & 1.59 & 0.83 & $1 \cdot 40$ & 0.65 \\
\hline 2 months & $1 \cdot 07^{* *}$ & $0 \cdot 44$ & $1 \cdot 25^{\star *}$ & 0.47 & $1 \cdot 47$ & 1.04 & $1 \cdot 34^{* *}$ & 0.58 & $1 \cdot 50$ & 0.65 \\
\hline 6 months & $1 \cdot 01^{* *}$ & 0.33 & $1 \cdot 20^{* *}$ & 0.47 & $1 \cdot 29$ & 0.87 & $1 \cdot 31^{\text {** }}$ & 0.52 & $1 \cdot 38$ & 0.65 \\
\hline \multicolumn{11}{|c|}{ LDL-C (mmol/l) } \\
\hline Baseline & $3 \cdot 72$ & 0.52 & $3 \cdot 56$ & $0 \cdot 81$ & $3 \cdot 55$ & $0 \cdot 81$ & 3.59 & $0 \cdot 67$ & $3 \cdot 64$ & $0 \cdot 84$ \\
\hline 2 months & 3.59 & 0.73 & $3 \cdot 12^{\star *}$ & 0.71 & $3 \cdot 29^{\text {** }}$ & 0.68 & $3 \cdot 21^{\star *}$ & 0.66 & $3 \cdot 79$ & 0.78 \\
\hline 6 months & $3 \cdot 56$ & $0 \cdot 76$ & $3 \cdot 13^{\star *}$ & 0.58 & $3 \cdot 31^{\star *}$ & $0 \cdot 70$ & $3 \cdot 15^{\star *}$ & 0.57 & 3.55 & 0.73 \\
\hline \multicolumn{11}{|c|}{ LDL peak density $(\mathrm{g} / \mathrm{l})$} \\
\hline Baseline & $1 \cdot 0317$ & 0.0031 & 1.0303 & 0.0031 & 1.0299 & 0.0036 & 1.0301 & 0.0036 & $1 \cdot 0302$ & 0.0032 \\
\hline 6 months & $1 \cdot 0280^{\star *}$ & 0.0021 & $1 \cdot 0281^{\text {** }}$ & 0.0021 & $1 \cdot 0286^{\star \star}$ & 0.0030 & $1 \cdot 0285^{\star *}$ & 0.0031 & $1 \cdot 0287^{\star \star}$ & 0.0032 \\
\hline \multicolumn{11}{|c|}{$\mathrm{HDL}-\mathrm{C}(\mathrm{mmol} / \mathrm{l})$} \\
\hline Baseline & $1 \cdot 22$ & 0.23 & $1 \cdot 16$ & 0.24 & $1 \cdot 25$ & 0.27 & $1 \cdot 22$ & $0 \cdot 30$ & $1 \cdot 19$ & 0.22 \\
\hline 2 months & $1 \cdot 24$ & 0.25 & $1.04^{\star *}$ & 0.21 & $1 \cdot 15^{\star \star}$ & 0.28 & $1.07^{\star *}$ & 0.24 & $1 \cdot 22$ & 0.24 \\
\hline 6 months & $1 \cdot 14$ & 0.32 & $0.98^{\star *}$ & $0 \cdot 15$ & $1.09^{* *}$ & 0.27 & $1 \cdot 02^{* *}$ & 0.25 & $1.04^{\star *}$ & $0 \cdot 20$ \\
\hline \multicolumn{11}{|c|}{ Glucose $(\mathrm{mmol} / \mathrm{l})$} \\
\hline Baseline & $5 \cdot 59$ & 0.45 & $5 \cdot 54$ & 0.49 & $5 \cdot 50$ & 0.52 & $5 \cdot 66$ & 0.66 & $5 \cdot 44$ & 0.37 \\
\hline 2 months & $5 \cdot 52$ & 0.43 & $5 \cdot 36$ & 0.51 & $5 \cdot 41$ & 0.49 & $5 \cdot 50$ & 0.53 & $5 \cdot 42$ & 0.43 \\
\hline 6 months & $5 \cdot 30^{\star}$ & 0.61 & $4 \cdot 95^{\star *}$ & 0.65 & $5 \cdot 23^{*}$ & 0.60 & $5 \cdot 23^{\star *}$ & 0.54 & $5 \cdot 18^{*}$ & 0.51 \\
\hline \multicolumn{11}{|c|}{ Insulin (pmol/l) } \\
\hline Baseline & $73 \cdot 2$ & $35 \cdot 1$ & $62 \cdot 2$ & $32 \cdot 4$ & $72 \cdot 3$ & $39 \cdot 1$ & $75 \cdot 7$ & $42 \cdot 7$ & $68 \cdot 1$ & $35 \cdot 6$ \\
\hline 2 months & $75 \cdot 2$ & $83 \cdot 6$ & $57 \cdot 2$ & 35.9 & $80 \cdot 1$ & $67 \cdot 1$ & $63 \cdot 7$ & $31 \cdot 8$ & $69 \cdot 2$ & $41 \cdot 0$ \\
\hline 6 months & $54 \cdot 8$ & $32 \cdot 4$ & 52.9 & $30 \cdot 2$ & $64 \cdot 6^{\star *}$ & 39.6 & $58 \cdot 5$ & $34 \cdot 8$ & $75 \cdot 9$ & $45 \cdot 0$ \\
\hline
\end{tabular}

LDL-C, LDL cholesterol; HDL-C, HDL cholesterol.

Mean values were significantly different from baseline: ${ }^{\star} P<0.05,{ }^{*} P<0.01$

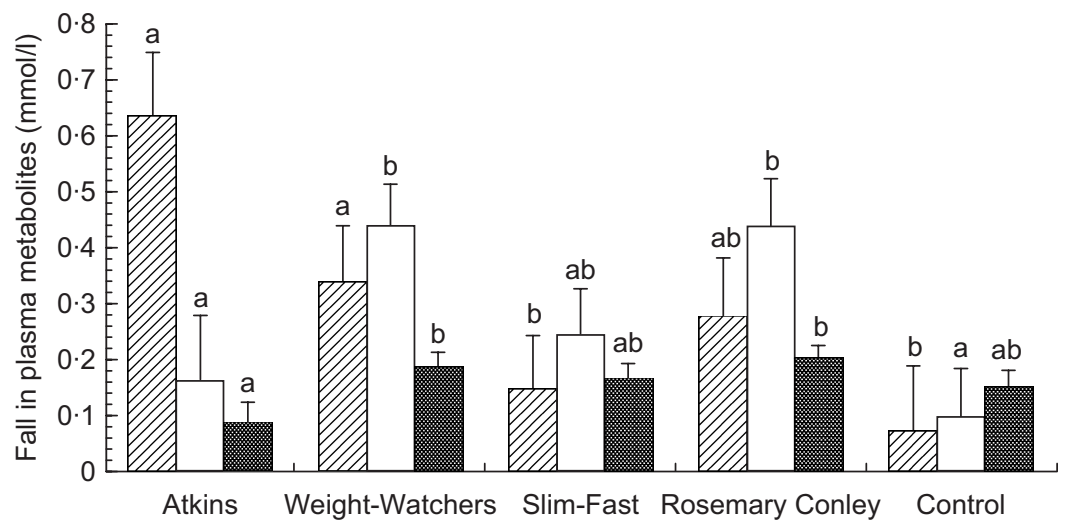

Fig. 1 Changes in plasma metabolites TAG (四), LDL cholesterol ( $\square$ ) and HDL cholesterol ( $\square$ ) over 6 months (basal minus 6-month level) in participants assigned to one of four dieting groups or a control group: UK multi-centred, randomised controlled trial of the effects of four commercially available weight-loss programmes on lipid-based CVD risk factors. Values are means with their standard errors represented by vertical bars (Atkins $n 33$, Weight Watchers $n$ 46, Slim-Fast $n$ 44, Rosemary Conley $n 41$, control $n 37) .{ }^{\text {a,b }}$ Mean values within each metabolite with unlike superscript letters were significantly different $(P<0 \cdot 05)$

for either diet or gender, although there was a trend $(P=0 \cdot 053)$ towards a dietary effect, with the largest mean glucose fall found for the Weight Watchers and Rosemary Conley diets. Similarly, insulin sensitivity (\%S), calculated by HOMA, showed no effect for either diet or gender, although there was a trend $(P=0 \cdot 095)$ towards a dietary effect, with an increase in insulin sensitivity in the dieting groups.

\section{Associations between changes in weight or waist circumference and changes in plasma insulin, glucose and lipids}

Associations between changes in weight or waist circumference (0-6 months) and changes in plasma insulin, glucose and lipids are shown in Table 4. Weight loss was significantly associated with changes in insulin, glucose and in the lipid profile at 6 months. Changes in waist 


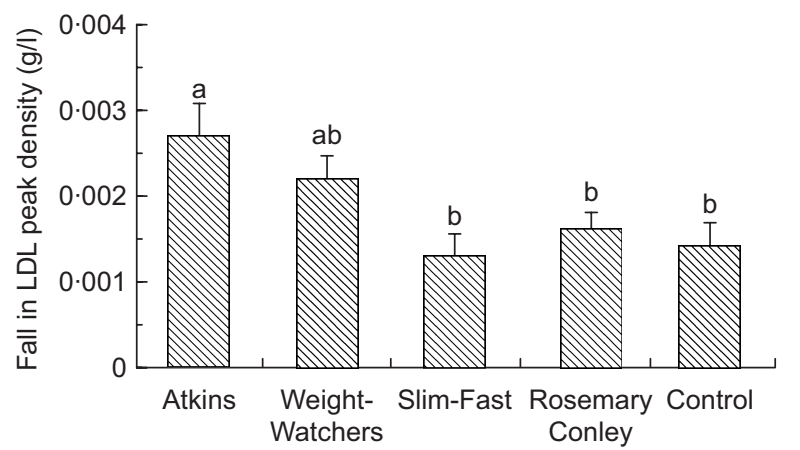

Fig. 2 Changes in peak LDL sub-fraction density over 6 months (basal minus 6-month level) in participants assigned to one of four dieting groups or a control group: UK multi-centred, randomised controlled trial of the effects of four commercially available weight-loss programmes on lipid-based CVD risk factors. Values are means with their standard errors represented by vertical bars (Atkins $n 33$, Weight Watchers $n 46$, Slim-Fast $n 44$, Rosemary Conley $n 41$, control $n 37$ ). ${ }^{\mathrm{a}, \mathrm{b}}$ Mean values with unlike superscript letters were significantly different $(P<0.05)$

circumference showed similar associations to those for weight loss with the exception of glucose. Correlations were generally stronger for men than for women.

\section{Discussion}

The present study was a multi-centred, randomised controlled trial of commercially available weight-loss strategies as they are likely to be followed by the public. Thus every effort was made to avoid investigator management of, or interference in, participants' food intakes. As discussed elsewhere ${ }^{(17)}$, there were no differences in diet, centre or gender in terms of the proportions of participants who completed or withdrew. The analysis of completers showed that, within each group, there was variable compliance resulting in a large range of weight loss for each of the four regimes, but all four diets tested were equally effective at promoting weight loss over 6 months.

Participants achieved approximately $70 \%$ of their final weight reduction after 2 months, and this was reflected in significant improvements in most metabolic variables by this time. Overall, weight loss was positively correlated with improvements in blood lipids with respect to plasma TAG, insulin, glucose, LDL-C values and LDL particle size. These findings are in agreement with many other studies $^{(15,23,24)}$ and emphasise the beneficial impact of negative energy balance and weight loss on metabolic factors related to CVD risk in overweight and obese subjects. The present study shows that this can be achieved through engagement with popular, commercially available weight-loss programmes in the UK. The similar efficacy of the four diets in terms of weight loss also afforded an opportunity to identify any effects of the
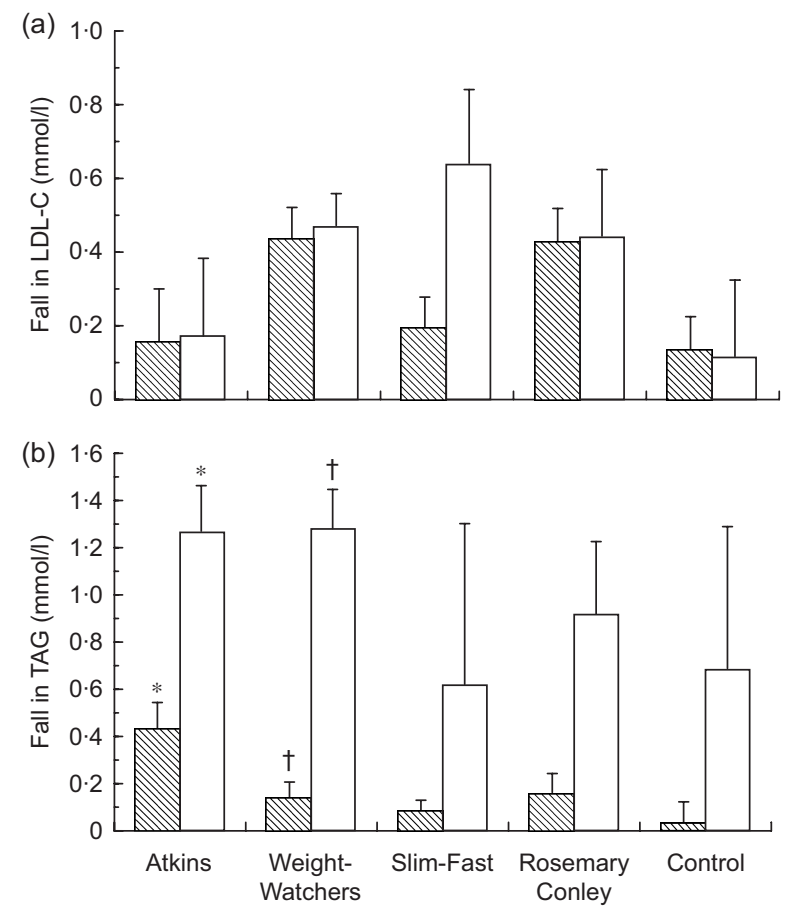

Fig. 3 Changes in (a) plasma LDL cholesterol (LDL-C) and (b)

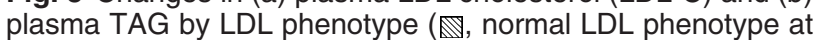
baseline, phenotype $A ; \square$, small dense LDL phenotype at baseline, phenotype B) over 6 months (basal minus 6-month level) in participants assigned to one of four dieting groups or a control group: UK multi-centred, randomised controlled trial of the effects of four commercially available weight-loss programmes on lipid-based CVD risk factors. Values are means with their standard errors represented by vertical bars (Atkins phenotype $A=24, B=9$; Weight Watchers $A=38, B=8$; Slim-Fast $A=39, B=5$; Rosemary Conley $A=34, B=7$; control $A=32, B=5)$. Mean values were significantly different between phenotypes: ${ }^{*} P<0.03, \uparrow P<0.01$

Table 4 Significant associations $(P<0.05)$ between change in weight or waist circumference (0-6 months) and change in plasma insulin, glucose or lipids: UK multi-centred, randomised controlled trial of the effects of four commercially available weight-loss programmes on lipid-based CVD risk factors

\begin{tabular}{|c|c|c|c|c|c|c|}
\hline & \multicolumn{3}{|c|}{ Weight } & \multicolumn{3}{|c|}{ Waist circumference } \\
\hline & All & Males & Females & All & Males & Females \\
\hline Insulin & 0.37 & 0.42 & 0.29 & 0.35 & 0.44 & 0.29 \\
\hline Glucose & 0.20 & $0 \cdot 28$ & $0 \cdot 19$ & NS & NS & NS \\
\hline TAG & 0.35 & 0.40 & 0.27 & 0.35 & 0.36 & 0.29 \\
\hline LDL-C & 0.26 & $0 \cdot 26$ & $0 \cdot 26$ & 0.23 & NS & $0 \cdot 30$ \\
\hline LDL peak density & 0.38 & 0.49 & $0 \cdot 19$ & 0.38 & 0.57 & 0.23 \\
\hline HDL-C & NS & NS & NS & NS & NS & NS \\
\hline
\end{tabular}

LDL-C, LDL cholesterol; HDL-C, HDL cholesterol.

Values are Pearson correlation coefficients $(r)$.

macronutrient composition of the diets on CVD risk markers that were independent of weight loss per se. The carbohydrate-restricted Atkins diet was markedly different in macronutrient composition compared with the other three diets (Weight Watchers, Rosemary Conley and 
Slim-Fast). When macronutrient intake was expressed as a percentage of total energy intake, the Atkins diet reduced carbohydrate intake substantially after 2 months and maintained a shift in the contribution of energy from carbohydrate to total fat and protein over 6 months. However, because the fall in energy intake resulted primarily from a reduction in carbohydrate-rich foods that were not replaced by protein or fat, in absolute terms, the intake of protein, total and saturated fat was largely unchanged from baseline values ${ }^{(16,17)}$. The Weight Watchers, Rosemary Conley and Slim-Fast diets showed similar shifts in macronutrient composition, with an initial decrease in the percentage energy from fat and an increase in the percentage energy from carbohydrate after 2 months, with some participants returning to baseline values after 6 months. The energy derived from protein showed a slight rise over time and remained higher than baseline values by the end of the study. These changes in dietary intake would indicate that the subjects were adhering to the diets to which they were assigned.

The increasing popularity of low-carbohydrate diets has prompted much debate over their potential to produce adverse effects on blood lipids and lipoproteins ${ }^{(25-27)}$. The evidence regarding LDL-C is equivocal. Early work demonstrated significant increases in LDL-C when obese subjects consumed a diet 'devoid of carbohydrate containing foods' for 4 weeks followed by a progressive intake of $5-8 \mathrm{~g}$ carbohydrate for the next 4 weeks ${ }^{(6)}$. Other shortterm studies (1-3 months) have shown no change in LDL-C levels ${ }^{(13,14)}$. The majority of longer-term studies have also shown no change in LDL-C after 6 months ${ }^{(4,5,7)}$, with one study reporting a significant decrease in LDL-C ${ }^{(8)}$. However, HDL-C levels have generally been shown to be maintained $^{(4,6,13-15)}$ or even improved ${ }^{(5,7,8)}$ on a low-carbohydrate diet. This finding is in contrast to the effects of low-fat, high-carbohydrate diets, which have been shown to consistently lower LDL-C but also decrease HDL-C ${ }^{(28)}$, even when accompanied by significant weight loss ${ }^{(29)}$. There is general agreement that low-carbohydrate diets are effective in lowering plasma TAG levels, especially if accompanied by weight loss ${ }^{(30)}$. Such diets are more effective at lowering TAG during weight loss than are lowfat, high-carbohydrate diets ${ }^{(4,5,13)}$. While the latter diets have been shown to either increase or decrease plasma TAG in the absence or presence of active weight loss respectively ${ }^{(31)}$, variations in study design, length of intervention (often 8 weeks or less) and dietary composition have confounded interpretation of this effect. Moreover, few studies have included a parallel control group or intervened in free-living subjects with commercially available diets. The dietary effects on blood lipids in the present study are in broad agreement with previous literature. Significant differences were clearly apparent between the low-carbohydrate Atkins group and two of the reduced-fat diets, Rosemary Conley and Weight Watchers. The latter had more pronounced effects in lowering LDL-C, while plasma TAG was reduced more effectively in the Atkins group. HDL-C was reduced in all groups with the notable exception of Atkins, but was unaffected by any of the diets in comparison to the control. Similarly, LDL-C was unaffected by the Atkins and Slim-Fast diets, whereas plasma TAG was unaffected by the Slim-Fast and Rosemary Conley diets, relative to the control. There were non-significant changes in some lipid parameters in the control group over 6 months that may have influenced between-group comparisons. Although there was no significant weight loss over time in the control group, other aspects of lifestyle such as exercise and activity were uncontrolled and subjects may have altered their behaviour in this respect. This might be expected given that all subjects in the control group had initially intended to lose weight as a prerequisite in volunteering for the study. The limited efficacy of these commercial weight-loss programmes in improving blood lipids may also be due, in part, to the very variable weight loss observed in all four dieting groups under free-living conditions, with some individuals being extremely successful and others less so ${ }^{(17)}$. Moreover, the weekly exercise class in the Rosemary Conley programme conferred no additional benefit in terms of weight loss or changes in blood lipids over a diet-alone programme of similar macronutrient composition, such as Weight Watchers.

High-fat, low-carbohydrate and low-fat, high-carbohydrate diets have been shown to produce differential effects on plasma LDL-C and TAG that depend on the initial type of LDL or LDL phenotype. High-fat, low-carbohydrate diets have been shown to increase LDL particle size and produce greater reductions in LDL-C and TAG in comparison to low-fat, high-carbohydrate diets in patients with a predominance of small, dense LDL. Likewise, the LDL-C-lowering capacity of a low-fat, high-carbohydrate diet is enhanced, and the potentially adverse TAG-raising effects of this diet limited, in individuals with a preponderance of this abnormal type of $\mathrm{LDL}^{(11,32)}$. In the present study, there was no evidence of an association between dietary effects on LDL-C and the predominant type of LDL. This may be explained by the surprisingly low expression of small, dense LDL in this overweight population at the outset of the study, and thus inadequate statistical power to identify such a relationship. In contrast, significantly greater reductions in plasma TAG were associated with a predominance of small, dense LDL particles in both the Atkins and Weight Watchers groups at baseline. This finding can be attributed to the close metabolic interrelationship between raised plasma TAG and the production of a more atherogenic species of small, dense $\operatorname{LDL}^{(9,10)}$.

Central weight gain is an established underlying cause of lipid abnormalities associated with increased CVD risk that can be corrected effectively through weight loss. Our study has demonstrated that commercial weight-loss programmes can help people with uncomplicated obesity 
and that relatively modest weight loss is associated with improvement in CVD risk factors. It was, however, relatively short-term (6-months) in terms of sustainable weight loss. The importance of strategies to maintain weight loss, in addition to successful dieting strategies, cannot be overemphasised. In this context, a 12-month follow-up of these participants, reported elsewhere ${ }^{(17)}$, pointed to an advantage of programmes based on group support in maintaining weight loss. While the present study showed all diets to be equal in their ability to promote weight loss, there was some disparity in their effects on blood lipids and lipoproteins. Despite concern over the possible adverse effects of low-carbohydrate diets, no detrimental effects were observed in subjects who were actively losing weight but also consuming a significantly greater proportion of their total energy as fat. Our findings also suggest that the cholesterol- and TAGlowering efficacy of these diets could be significantly improved by the recognition and targeting of subjects with a small, dense LDL phenotype.

\section{Acknowledgements}

We wish to thank Dr Ian G. Davies for the blood analysis; Rebecca Hiscutt, Anne Herriot and Manana Stanley for the diet analysis; and Professor M.B.E. Livingstone for her assistance with the study. The authors wish to acknowledge the British Broadcasting Corporation for sponsorship of this study, and all the participants who persevered with their dietary interventions. None of the authors has any conflicts of interest.

\section{References}

1. Food Standards Agency and Department of Health (2004) National Diet and Nutrition Survey: Adults Aged 19 to 64 Years. vol. 5: Summary Report. London: The Stationery Office.

2. Klein S, Burke LE, Bray GA, Blair S, Allison DB, Pi-Sunyer $\mathrm{X}$, Hong Y \& Eckel RH (2004) Clinical implications of obesity with specific focus on cardiovascular disease: a statement for professionals from the American Heart Association Council on Nutrition, Physical Activity and Metabolism: endorsed by the American College of Cardiology Foundation. Circulation 110, 2952-2967.

3. Roche HM (1999) Dietary carbohydrates and triacylglycerol metabolism. Proc Nutr Soc 58, 201-207.

4. Samaha FF, Iqbal N, Seshadri P, Chicano KL, Daily DA, McGrory J, Williams T, Williams M, Gracely EJ \& Stern L (2003) A low-carbohydrate diet as compared with a low-fat diet in severe obesity. $N$ Engl J Med 348, 2074-2081.

5. Foster GD, Wyatt HR, Hill JO, McGuckin BG, Brill C, Mohammed BS, Szapary PO, Rader DJ, Edman JS \& Klein S (2003) A randomised trial of a low-carbohydrate diet for obesity. N Engl J Med 348, 2082-2090.

6. Larosa JC, Fry AG, Muesing R \& Rosing DR (1980) Effects of high-protein, low-carbohydrate dieting on plasma lipoproteins and body weight. J Am Diet Assoc 77, 264-270.
7. Brehm BJ, Seeley RJ, Daniels SR \& D'Alessio DA (2003) A randomized trial comparing a very low carbohydrate diet and a calorie-restricted low fat diet on body weight and cardiovascular disease risk factors in healthy women. J Clin Endocrinol Metab 88, 1617-1623.

8. Westman EC, Yancy WS, Edman JS, Tomlin KF \& Perkins CE (2002) Effect of 6-month adherence to a very low carbohydrate diet programme. Am J Med 113, 30-36.

9. Austin MA, King MC, Vranizan KM \& Krauss RM (1990) Atherogenic lipoprotein phenotype. A proposed genetic marker for coronary heart disease risk. Circulation 82, 495-506.

10. Griffin BA, Freeman DJ, Tait GW, Thomson J, Caslake MJ, Packhard CJ \& Shepherd J (1994) Role of plasma triglyceride in the regulation of plasma low density lipoprotein (LDL) subfractions. Relative contribution of small, dense LDL subfractions to coronary heart disease risk. Atherosclerosis 106, 241-253.

11. Krauss RM \& Dreon DM (1995) Low-density-lipoprotein subclasses and response to a low-fat diet in healthy men. Am J Clin Nutr 62, 478S-487S.

12. Dreon DM, Fernstrom HA, Miller B \& Krauss RM (1995) Apolipoprotein $\mathrm{E}$ isoform phenotype and LDL subclass response to a reduced-fat diet. Arterioscler Thromb Vasc Biol 15, 105-111.

13. Sharman MJ, Gomez AL, Kraemer WJ \& Volek JS (2004) Very low-carbohydrate and low-fat diets affect fasting lipids and postprandial lipemia differently in overweight men. J Nutr 134, 880-885.

14. Volek JS, Sharman MJ, Gomez AL, DiPasquale C, Roti M, Pumerantz A \& Kraemer WJ (2004) Comparison of very low-carbohydrate and low-fat diets on fasting lipids, LDL subclasses, insulin resistance, and postprandial lipemic responses in young women. J Am Coll Nutr 23, 177-184.

15. Dansinger ML, Gleason JA, Griffith JL, Selker HP \& Schaefer EJ (2005) Comparison of the Atkins, Ornish, Weight Watchers, and Zone diets for weight loss and heart disease reduction: a randomized trial. JAMA 293, 43-53.

16. Boley R, Herriot A, DeLooy A, Fox K, Bonham MP, MacDonald I, Millward DJ, Morgan LM \& Truby H (2004) Dietary changes induced by the Atkins diet. Proc Nutr Soc 63, 82a.

17. Truby H, Baic S, DeLooy A, Fox KR, Macdonald I, Morgan L, Taylor MA \& Millward DJ (2006) A randomised controlled trial of four commercial weight loss programmes in the UK: initial findings from the BBC Diet Trials. BMJ 322, 1309-1311.

18. Atkins R (1999) Dr Atkins' New Diet Revolution. South Dakota: Vermillion.

19. Matthews DR, Hosker JP, Rudenski AS, Naylor BA, Treacher DF \& Turner RC (1985) Homeostasis model assessment: insulin resistance and $\beta$-cell function from fasting plasma glucose and insulin concentrations in man. Diabetologia 28, 412-419.

20. Davies IG, Graham JM \& Griffin BA (2003) Rapid separation of LDL subclasses by iodixanol gradient ultracentrifugation. Clin Chem 49, 1865-1872.

21. Griffin BA, Caslake MJ, Yip B, Tait GW, Packard CJ \& Shepherd J (1990) Rapid isolation of low density lipoprotein (LDL) subfractions from plasma by density gradient ultracentrifugation. Atherosclerosis 83, 59-67.

22. Newman DJ, Thakkar H, Edwards RG, Wilkie M, White T, Grubb AO \& Price CP (1995) Serum cystatin C measured by automated immunoassay: a more sensitive marker of changes in GFR than serum creatinine. Kidney Int $\mathbf{4 7}$, 312-318.

23. Poobalan A, Aucott L, Smith WCS, Avenell A, Jung R, Broom J \& Grant AM (2004) Effects of weight loss in overweight/obese individuals and long-term lipid outcomes - a systematic review. Obes Rev 5, 43-50. 
24. Dattilo AM \& Kris-Etherton PM (1992) Effects of weight reduction on blood lipids and lipoproteins: a meta-analysis. Am J Clin Nutr 45, 320-328.

25. Acheson KJ (2004) Carbohydrate and weight control: where do we stand? Curr Opin Clin Nutr Metab Care 7 , 485-492.

26. Willett WC (2004) Reduced-carbohydrate diets: no role in weight management? Ann Intern Med 18, 836-837.

27. Volek JS, Sharman MJ \& Forsythe CE (2005) Modification of lipoproteins by very low-carbohydrate diets. J Nutr $\mathbf{1 3 5}$, 1339-1342.

28. Poppitt SD, Keough GF, Prentice AM, Williams DE, Sonnemans HM, Valk EE, Robinson E \& Wareham NJ (2002) Long-term effects of ad libitum low-fat, highcarbohydrate diets on body weight and serum lipids in overweight subjects with metabolic syndrome. Am J Clin Nutr 75, 11-20.
29. Pelkman CL, Fishell VK, Maddox DH, Pearson TA, Mauger DT \& Kris-Etherton PM (2004) Effects of moderate-fat (from monounsaturated fat) and low-fat weight-loss diets on serum lipid profiles in overweight and obese men and women. Am J Clin Nutr 79, 203-212.

30. Zulet MA, Berkenpas ME \& Martinez JA (2005) Comparison of dietary approaches to treat obesity based on different carbohydrate/fat content: impact on weight loss and lipid profile. Curr Nutr Food Sci 1, 13-21.

31. Yu-Poth S, Zhao G, Etherton T, Naglak M, Jonnalagadda S \& Kris-Etherton PM (1999) Effects of the National Cholesterol Education program's Step I and Step II dietary intervention Programs on cardiovascular disease risk factors: a meta-analysis. Am J Clin Nutr 69, 632-646.

32. Dreon DM, Fernstrom HA, Williams PT \& Krauss RM (1997) LDL subclass patterns and lipoprotein response to a lowfat, high-carbohydrate diet in women. Arterioscler Thromb Vasc Biol 17, 707-714. 